\title{
COMPOSIÇÃO CORPORAL DE INDIVÍDUOS PRATICANTES DE HANDEBOL EM CADEIRA DE RODAS
}

\author{
Raquel L. Cabral ${ }^{\star}$, Mariane Borges, José I. Gorla.
}

\begin{abstract}
Resumo
A lesão medular causa inúmeras alterações físicas no indíviduo, tanto no seu período agudo quanto crônico, uma delas é a composição corporal. O estudo teve como objetivo avaliar os efeitos da prática de Handebol em Cadeira de Rodas (HCR) na composição corporal de indivíduos com Lesão da Medula Espinhal (LME) utilizando os métodos: absorciometria radiológica de dupla energia e antropometria. $O$ estudo teve 5 participantes com lesão crônica e que praticavam HCR duas vezes por semana. A avaliação ocorreu antes e após um período de 5 meses e foi realizada análise estatística. Como resultado, os atletas não apresentaram alterações significativas na composição corporal, contudo a manutenção dos valores avaliados já demonstra um aspecto positivo para essa população que tende a apresentar sedentarismo e tendência à obesidade. Concluímos que não houve mudança na composição corporal para essa população e que a baixa intensidade e frequência semanal dos treinos podem ser fatores limitantes de resultados mais expressivos, assim como o tamanho da amostra.
\end{abstract}

\section{Palavras-chave:}

Handebol de Cadeira de Rodas, Composição Corporal, Absorciometria Radiológica de Dupla Energia.

\section{Introdução}

A LME é uma das causas mais comuns da deficiência física no Brasil. Inúmeras alterações fisiológicas ocorrem no período agudo e crônico deste tipo de lesão, dentre elas cabe destacar a composição corporal a qual apresenta um aumento da massa gorda e redução da massa. Sendo assim, este estudo teve como objetivo avaliar os efeitos da prática do HCR na composição corporal de indivíduos com LME ao nível de paraplegia.

\section{Resultados e Discussão}

Participaram deste estudo cinco indivíduos com LME crônica e que praticassem HCR, no mínimo, duas vezes por semana num período de aproximadamente cinco meses. Todos os procedimentos foram aprovados pelo Comitê de Ética em Pesquisa da Faculdade de Ciências Médicas da UNICAMP sob o número 1.987.980. A intervenção ocorreu com a avaliação inicial e final de variáveis antropométricas e da composição corporal. Os pesquisadores avaliaram o tempo total de cada sessão de treino e a percepção subjetiva de esforço (PSE), adaptada por Foster et al. ${ }^{1}$

Tabela 1. Medidas antropométricas pré e pós prática de HCR,.

\begin{tabular}{ccccccc}
\hline \multirow{2}{*}{ No } & \multicolumn{2}{c}{$\mathbf{M C}(\mathbf{K g})$} & \multicolumn{2}{c}{ IMC $\left(\mathbf{K g} / \mathbf{m}^{2}\right)$} & \multicolumn{2}{c}{$\sum$ pregas $(\mathbf{m m})$} \\
\cline { 2 - 7 } & PRÉ & PÓS & PRÉ & PÓS & PRÉ & PÓS \\
\hline 1 & 71,7 & 78,7 & 24,8 & 27,2 & 202 & 226,8 \\
2 & 83,8 & 82,7 & 28,3 & 28,0 & 216,8 & 192,4 \\
3 & 86,6 & 83,1 & 29,6 & 28,4 & 193,6 & 187,3 \\
4 & 78,8 & 77,8 & 26,3 & 26,0 & 154,6 & 178 \\
5 & 96,6 & 93 & 28,2 & 27,2 & 311,4 & 227
\end{tabular}

Legenda: $M C=$ massa corporal; $E S T=$ estatura; $I M C=$ índice de massa corporal; $\Sigma$ 9pregas= somatória de 9 pregas cutâneas.

Por meio dos resultados podemos identificar que não houveram mudanças significativas nas variáveis antropométricas e da composição corporal, contudo, se houvesse declínio dessas variáveis, poderia ser afetado negativamente tanto os aspectos relacionados à saude quanto o desempenho motor ${ }^{2}$.
Tabela 2. Composição corporal predita por DXA pré e pós prática de HCR.

\begin{tabular}{cccccc}
\multicolumn{2}{c}{ INDICES DE ADIPOSIDADE } & \multicolumn{2}{c}{ INDICES MM+CMO } \\
\hline \multicolumn{2}{c}{$\%$ A } & \multicolumn{2}{c}{ AND/GEN } & \multicolumn{2}{c}{$\begin{array}{c}\text { APPEN } \\
\text { (MM+CMO)/Alt }\end{array}$} \\
\hline PRÉ & PÓS & PRÉ & PÓS & PRÉ & PÓS $^{\text {PRE }}$ \\
\hline 28.7 & 28.7 & 0.610 & 0.630 & 6.9 & 7.5 \\
36.7 & 39.9 & 1.120 & 1.070 & 7.1 & 6.6 \\
26.2 & 26.6 & 1.210 & 1.190 & 10.3 & 9.9 \\
24 & 24.1 & 1.150 & 1.150 & 8.19 & 8.6 \\
37.6 & 36.1 & 0.870 & 0.820 & 6.79 & 6.7 \\
\hline
\end{tabular}

Legenda: $\% G=$ Percentual de gordura corporal; $A n d / G e n=$ razão androide genoide; APPEN $(\mathrm{MM}+\mathrm{CMO}) / \mathrm{Alt}^{2}=$ Massa magra apendicular

Podemos citar a baixa frequência semanal e a intensidade do treino como insuficientes para provocarem adaptações mais expressivas. Como fatores limitantes do estudo, podemos citar o tamanho da amostra e a dificuldade de compor uma amostra tão específica com mais participantes.

\section{Conclusões}

Através deste estudo conclui-se que atividades realizadas duas vezes por semana, através da prática do HCR não trouxeram mudanças significativas na composição corporal da população com LME estudada. Entretanto, foi observada a manutenção destas variáveis, o que configura um dado positivo para esses indivíduos que têm tendência à obesidade.

\section{Agradecimentos}

Aos atletas de Handebol em Cadeira de Rodas.

Trabalho realizado com bolsa $\mathrm{PIBIC/CNPq}$.

${ }^{1}$ Foster, C.; Heimann, K.M; Esten, P.L; Brice, G.; Porcari, J.P. Differences in perceptions of training by coaches and athletes. South African J Sports Med 2001;8:3-7.

${ }^{2}$ Borges, M.; Costa e Silva, A. A. ; Faria, F. R. ; Godoy, P. S. ; Melo, E. R. B.; Calegari, D. R. ; Gorla, J.I . Body composition and motor performance in wheelchair handball. Revista Brasileira de Cineantropometria \& Desempenho Humano, v. 17, p. 204-213, 2017. 